\title{
SERAT PRABANGKARA KARYA KI PADMASUSASTRA TINJAUAN PSIKOLOGI SASTRA DAN NILAI PENDIDIKAN KARAKTER
}

\author{
Oleh: \\ Onok Yayang Pamungkas \\ Universitas Maarif Nahdlatul Ulama Kebumen
}

\begin{abstract}
Abstrak
Tujuan dari penelitian ini adalah untuk menguji aspek psikologis karakter dalam serat Novel Prabangkara dengan Ki Padmasusastra menggunakan psikologi tinjauan pustaka. Bentuk penelitian deskriptif kualitatif dengan menggunakan strategi analisis isi. Sumber data yang digunakan dalam bentuk dokumen. Teknik pengumpulan data yang dengan analisis isi. Validasi data menggunakan triangulasi teori dan triangulasi data. Teknik analisis data meliputi reduksi data, penyajian data, menggambar Kesimpulan dan verifikasi data. Hasil Menunjukkan bahwa karakter dalam analisis baru didasarkan pada proses psikologis masingmasing karakter yang dipengaruhi oleh faktor dalam dan faktor luar. Melalui analisis karakter menggunakan pendekatan psikologis Sigmund Freud (id, ego dan superego), kepribadian masing-masing karakter dapat dipahami dan memberikan efek realistis dalam pendidikan karakter. Ini adalah bagian dari kemampuan penulis untuk menggambarkan disposisi dari tokoh dalam karyanya. Kesimpulan dari penelitian ini adalah aspek psikologis karakter dalam serat Novel Prabangkara oleh Ki Padmasusastra dapat ditinjau restoran dengan menggunakan teori psikologi Sigmund Freud.
\end{abstract}

Kata kunci: Serat Prabangkara, Psikologi Sastra, Pendidikan Karakter.

\section{Pendahuluan}

Karya sastra yang menampilkan berbagai karakter manusia sejatinya menampilkan kondisi kejiwaan manusia meskipun berupa cerita fiktif. Hal tersebut berarti bahwa karya sastra juga berkaitan dengan ilmu kejiwaan atau psikologi. Untuk memahami aspekaspek kejiwaan, dibutuhkan pengetahuan tentang psikologi, karena psikologi mengandung makna ilmu pengetahuan tentang jiwa atau ilmu jiwa. Penelitian dengan pendekatan psikologi terhadap karya sastra untuk memahami dan menafsirkan karya sastra dari sisi psikologi. Psikologi sastra berarti menelaah karya sastra yang diyakini mencerminkan proses dan aktivitas kejiwaan (Minderop, 2011:54). Teori yang sering digunakan dalam penelitian psikologi sastra adalah teori psikoanalisis yang dicetuskan oleh Sigmund Freud.

Konsep psikoanalisis itu sendiri sebenamya adalah konsep yang sudah lama ada. Konsep tersebut pertama kali diperkenalkan oleh Sigmund Freud. Psikoanalisis bukan merupakan keseluruhan dan ilmu jiwa, tetapi merupakan suatu cabang dari ilmu jiwa. Dalam teori psikoanalisis ini, aspek kepribadian meliputi tiga hal, yaitu id, ego, dan superego. Id 
adalah sistem kepribadian yang paling dasar, sistem yang di dalamnya terdapat naluri-naluri bawaan. Ego adalah sistem kepribadian yang bertindak sebagai pengarah individu kepada dunia objek dari kenyataan, dan menjalankan fungsinya berdasarkan prinsip kenyataan (reality principle). Superego adalah sistem kepribadian yang berisikan nilai-nilai dan aturanaturan yang sifatnya evaluatif (menyangkut baik buruk). Relevansi analisis psikologis diperlitkan pada saat manusia kehilangan pengendalian psikologis. Masalah-masalah dalam realitas kehidupan manusia tersebut tidak tertutup kemungkinannya berefleksi dalam karya sastra. Pengungkapan realitas dalam karya sastra melalui medium bahasa yang figuratif memiliki kemampuan yang jauh lebih luas dalam mengungkap masalah-masalah yang ada dalam masyarakat.

Karya sastra dikatakan bermanfaat apabila dengan membaca karya sastra tersebut, pembaca dapat menarik pelajaran yang berharga, yang memuat nilai-nilai luhur dan dapat digunakan pertimbangan untuk menjalani kehidupan. Hal tersebut menunjukkan bahwa karya sastra erat hubungannya dengan praktik pendidikan. Berkaitan dengan upaya memahami dan mengungkap aspek kejiwaan, imajinasi kreativitas pengarang, serta nilai-nilai yang terkandung dalam sebuah teks karya sastra, dalam objek penelitian ini dipilih karya besar dari Ki Padmasusastra yang berjudul Serat Prabangkara.

Serat Prabangkara merupakan salah satu karya sastra Jawa berbentuk prosa dengan menggunakan bahasa Jawa krama dan di tengah-tengah cerita terdapat tembang macapat yang menambah keindahan cerita tersebut. Serat Prabangkara dikarang oleh Ki Padmasusastra. Menurut Supardjo (dalam makalah seminarnya, 2010) menjelaskan bahwa Ki Padmasusastra adalah orang yang sangat memberi perhatian lebih pada kasusasteraan Jawa dizamannya. Terlepas dari hal-hal yang telah disebutkan di atas, dalam Serat Prabangkara juga menyajikan nilai pendidikan karakter yang digunakan sebagai tuntunan masyarakat. Berangkat dari hal-hal tersebut maka penulis melakukan tinjauan psikologi sastra, khususnya mengenai karakter tokoh dalam Serat Prabangkara yang muncul melalui realitas cerita, untuk mengungkap nilai-nilai pendidikan karakter yang masih relevan dengan pembentukan perilaku generasi muda masa kini.

Adapun tujuan yang ingin dicapai dari penelitian ini adalah Mendeskripsikan struktur karya sastra dalam Serat Prabangkara karya Ki Padmasusastra; Mendeskripsikan id dalam Serat Prabangkara karya Ki Padmasusastra; Mendeskripsikan ego dalam Serat Prabangkara karya Ki Padmasusastra; Mendeskripsikan superego dalam Serat Prabangkara karya Ki 
Padmasusastra; dan Mendeskripsikan nilai pendidikan karakter yang terdapat dalam Serat Prabangkara karya Ki Padmasusastra.

\section{Metode Penelitian}

Metode penelitian yang digunakan dalam penelitian ini adalah kualitatif deskriptif. Objek penelitian ini adalah karya sastra, sehingga dapat dikatakan bahwa penelitian ini menggunakan metode kualitatif deskriptif untuk penelitian sastra. Jenis penelitian ini adalah penelitian kepustakaan (library research). Sumber data dalam penelitian ini adalah naskah Serat Prabangkara. Teknik pengumpulan data yang digunakan dalam penelitian ini adalah teknik analisis isi. Validasi data yang digunakan adalah trianggulasi data dan trianggulasi teori. Hal ini dilakukan karena untuk mengadakan suatu pengecekan data agar data yang dikumpulkan atau dianalisis semakin mantap dan tidak ada keraguan atau sahih. Teknik analisis data dalam penelitian ini melalui reduksi data, sajian data, penarikan kesimpulan dan verifikasi.

\section{Hasil Penelitian dan Pembahasan}

\section{Hasil Penelitian}

\section{Struktur Serat Prabangkara}

Tema dalam Serat Prabangkara penulis menyimpulkan bahwa novel tersebut bertemakan tentang percintaan. Diceritakan bahwa kepergian Rara Apyu masuk kedalam hutan belantara. Linangan airmata terus menemani perjalananya. Berikut kutipan Sang Putri yang dapat menunjukkan tema percintaan dalam Serat Prabangkara:

\section{Maskumambang}

Dhuh pangeran dununge katresnan

mami

Baya tan supena

Dasine kawelas asih

Angambah wana wulusan

Terjemahan:

Duh pangeran pelabuhan cintaku

Tidaklah bermimpi

Diriku berbelas kasihan

Menjamah hutan wulusan

\section{Dalam Tokoh dan Penokohan}

Serat Prabangkara menampilkan tokoh-tokoh yang berasal dari latar belakang sosial dan budaya yang berbeda-beda. Di bawah ini akan diuraikan tokoh-tokoh yang mempunyai 
peran dalam jalannya cerita atau tokoh yang sering muncul beserta karakter berdasarkan peran dan fungsinya yang terdapat dalam Serat Prabangkara. Berikut contoh tokoh dan penokohan dalam serat prabangkara:

a. Pangeran Adipati Prabangkara

Pangeran Adipati Prabangkara adalah tokoh utama protagonis dalam novel ini. Ketika masih kecil Pangeran Adipati Prabangkara digambarkan sebagai anak yang sangat menawan dan sangat memukau. Pelukisan watak Pangeran Adipati Prabangkara ini menggunakan metode Direct Author Analysis; pengarang secara langsung menganalisis atau melukiskan keadaan pelaku. Nampak pada kutipan dibawah ini:

$$
\begin{aligned}
& \text { sang rajaputra sakalangkung } \\
& \text { dinama-dama, kalis ing roga } \\
& \text { walagang kados siniram ing toya } \\
& \text { gege, cinitra warnanipun sang } \\
& \text { pangeran pindha bang-bang } \\
& \text { mudhun saking ardi ruruh sêmu } \\
& \text { jatmika mêrak ati,... (H2Pl) }
\end{aligned}
$$

Terjemahannya:

$$
\begin{gathered}
\text { Sang putra raja sangat diidamidamkan, } \\
\text { badanya cepat tumbuh } \\
\text { besar bagaikan disiram air } \\
\text { kehidupan, diibaratkan wujud } \\
\text { Sang Pangeran bagaikan matahari } \\
\text { kemerah-merahan yang turun dari } \\
\text { gunung dengan anggun dan } \\
\text { sangat memikat hati. }
\end{gathered}
$$

b. Rara Apyu

Semasa kecil Rara Apyu sudah terlihat kalau kelak akan menjadi orang yang terkemuka di bumi. Wajahnya sangat cantik, tubuhnya langsing, kulitnya berwarna kuning langsat, dan mukanya bersinar bagaikan bintang. Secara fisik sosok Rara Apyu gigambarkan sebagai wanita yang sangat sempurna. Nampak pada kutipan dibawah ini:

$$
\begin{aligned}
& \text {...Rara Apyu, endah ing warni } \\
& \text { sanadyan dèrèng pêcah } \\
& \text { pamoripun, sampun angantawisi } \\
& \text { yèn badhe pinunjul ing bumi, } \\
& \text { cinitra warnanipun Rara Apyu, } \\
& \text { sariranipun singsêt amênjalin } \\
& \text { kuning wênês maya-maya lumêr } \\
& \text { apindha pradapaning angsoka, } \\
& \text { wadananipun mancorong pindha } \\
& \text { kartika mabangun,...(H3) }
\end{aligned}
$$




\section{Terjemahannya: \\ ...Rara Apyu, indah mujudnya \\ walaupun belum pecah \\ kewibawaannya. Sudah terlihat \\ jika kelak akan terkemuka di \\ Bumi. Digambarkan mujudnya \\ Rara Apyu, tubuhnya langsing, \\ kulitnya berwarna kuning langsat, \\ dan mukanya bersinar bagaikan \\ bintang yang merekah.}

Alur memegang peranan penting dalam cerita karena merupakan kerangka cerita. Alur

atau plot mempunyai tujuh tahapan yaitu eksposisi, inciting moment, rising action, complication, klimaks, falling action dan denonement. Dalam Serat Prabangkara terdapat lima episode penting yang dikisahkan oleh tokohtokoh sentralnya. Namun disini penulis paparkan salah satu bentuk analisis alur dalam Serat Prabangkara. Episode pertama dengan tokoh sentral Pangeran Adipati Prabangkara dan Rara Apyu dikisahkan dengan alur sebagai berikut:

a. Tahap Eksposisi I

Pada tahap ini, pengarang mengawali cerita dengan memperkenalkan situasi negara Indhu dan rajanya yang bernama Prabu Ondakara. Pangeran Adipati Prabangkara disekolahkan bersama teman-temannya yang di situ berbaur antara anak laki-laki dan perempuan. Setelah beberapa lama, Ia mulai timbul rasa cinta kepada teman sekolahnya yang bernama Rara Apyu yang merupakan teman di sekolahnya.

\section{b. Tahap Inciting Moment I}

Peristiwa pada tahap ini ditandai ketika Prabu Ondakara merasa curiga kepada perilaku anaknya yaitu Pangeran Adipati Prabangkara yang telah lama meninggalkan tidak ikut dalam pertemuan jajaran pemerintahan di kerajaan.

c. Tahap Rising Action I

Tahap penanjakan konflik ini ditandai oleh peristiwa ketika Prabu Ondakara hendak menjodohkan anaknya dengan putri raja atau keluarga raja. Lalu kabar tersebut disampaikan oleh Geniraga yang merupakan kakak dari Rara Apyu, sehingga hal tersebut membuat sedih Rara Apyu.

\section{d. Tahap Complication I}

Tahap ini ditengarai ketika setelah mengetahui anaknya sudah tidak ada dirumah, lalu Ki Jurutaman segera melaporkan hal tersebut kepada Pangeran Adipati Prabangkara. Hal itu semakin menambah kebingungan Sang Pangeran. 


\section{e. Tahap Klimaks I}

Klimaks I ini ditandai ketika Pangeran Adipati Prabangkara mencari Rara Apyu. Setelah beberapa waktu tapi belum bisa menemukannya. Lalu Ia menggukan ilmu penciuman untuk mencari Rara Apyu. Setelah sesampai di pinggir sendang Pangeran Adipati Prabangkara menemukan Rara Apyu. Kemudian tanpa sepengetahuan Rara Apyu, dipeluklah oleh Pangeran Adipati Prabangkara dari belakang. Rara Apyu sangat terkejut namun bercampur rasa haru dan senang. Mereka lalu saling perpelukan.

\section{f. Tahap Falling Action I}

Tahap falling action I ditandai pada saat Pangeran Adipati Prabangkara dan Rara Apyu mulai berduaan di tepi sendang. Dalam pembicaraannya mereka merencanakan untuk tidak kembali ke kerajaan, namun tetap hidup bersama dan bisa menikah.

\section{Aspek Id dalam Serat Prabangkara}

Dalam prosesnya $i d$ akan berusaha memuaskan keinginan atau menyerahkan kepada ego. Aspek id ini salah satunya digambarkan oleh para tokoh dalam Serat Prabangkara yang nampak pada kutipan di bawah ini:

$$
\begin{gathered}
\text { “Karepku: yen kowe condhong, } \\
\text { aku arep ambanjurake oncat saka } \\
\text { tetekemaning wong atuwaku, } \\
\text { kaya-kaya aku bisa urip kanthi } \\
\text { seneng anggawa sangu kalawan } \\
\text { pawitaning kapinteranaku, } \\
\text { anggere sakaroron karo kowe,...”(H28) } \\
\text { Terjemahanya: } \\
\text { Keinginanku, jika kamu mau, aku } \\
\text { akan melanjutkan pergi dari } \\
\text { cengkeraman orang tuaku, } \\
\text { seakan-akan aku bisa hidup } \\
\text { sendiri dengan senang dengan } \\
\text { bekal kepintaranku asalkan dapat } \\
\text { berdua denganmu,... }
\end{gathered}
$$

Hasil analisis ini menunjukkan bahwa karena cinta Pangeran Adipati Prabangkara tidak mendapat persetujuan dari ayahnya, maka Pangeran Adipati Prabangkara ingin memilih pergi dengan Rara Apyu untuk menjalani hidup mandiri di tempat lain. Dengan demikian Ia rela meninggalkan tugas kerajaan dan keluarga asalkan dapat selalu bersama dengan Rara Apyu. Hal ini merupakan kebutuhan rasa cinta yang bersifat egois dari diri Pangeran Adipati Prabangkara yang ingin terpenuhi. 


\title{
3. Aspek Ego dalam Serat Prabangkara
}

Ego merupakan aspek dari pada kepribadian dan timbul karena kebutuhan organisme untuk berhubungan dengan dunia kenyataan. Aspek ego ini salah satunya digambarkan oleh para tokoh dalam Serat Prabangkara yang nampak pada kutipan di bawah ini:

\author{
"Kowe arêp takjak lunga rangkat \\ mênyang tanah kang ora \\ kêbawah kaparentah ing nagara \\ Indhu, ing kana aku lan kowe \\ bakal gêndhon rukon ing \\ salawas-lawase." (H29) \\ Terjemahannya: \\ Kamu akan saya ajak pergi untuk \\ kawin lari ke tempat yang tidak \\ masuk dalam kuasa pemerintahan \\ Negara Indhu, di sana aku dan \\ kamu akan hidup damai selamalamanya.
}

Tekat Pangeran Adipati Prabangkara sangat kuat untuk dapat hidup bersama dengan Rara Apyu, sehingga mendorong ego untuk merealisasikan keinginannya yang sudah tidak dapat dibendung lagi. Setelah Pangeran Adipati Prabangkara bertemu dengan Rara Apyu di Sendang lalu Ia hendak mengajak pergi Rara Apyu untuk meninggalkan kerajaan dan menikah di suatu tempat. Hal tersebut dilakukan oleh Pangeran Adipati Prabangkara untuk merealisasikan $i d$ berdasarkan prinsip pemuasan kebutuhan.

\section{Aspek Superego dalam Serat Prabangkara}

Superego cenderung untuk menentang baik id maupun ego dan membuat dunia menurut konsepsi yang ideal. Dalam Serat Prabangkara, aspek superego Nampak pada kutipan di bawah ini:

\footnotetext{
"Aku iya amrayogakake lêstarine sêdyamu kang marang kautaman, sarta aku narima bakal anampani sih ana tibaning môngsa kang pinarêngake dening Allah, amarga aku ora bisa anglakoni among suka saka pamardining yayah rena kang nyimpang saka karêpe kang nglakoni, ,...” (H29)

Terjemahannya:

Saya juga membenarkan baiknya niatmu yang sesuai dengan jalan kebaikan, dan saya menerima akan menerima kasih sayang pada suatu saat yang diberikan oleh Allah, karena saya tidak bisa
} 
melakukan perintah ayah yang tidak sesuai dengan keinginan yang melakukan, ,...

Kutipan di atas tergambar superego yaitu dari niat Pangeran Adipati Prabangkara untuk mengajak Rara Apyu pergi dan menjalani hidup baru memang sudah dipikirkan terlebih dahulu dengan memertimbangkan hal-hal menjadi penyebab maupun dampaknya. Sehingga dampak buruk yang akan diterima oleh Pangeran Adipati Prabangkara memang sudah dipertimbangkan dengan baik.

\section{Nilai Pendidikan Karakter dalam Serat Prabangkara}

Sebagai sebuah karya sastra, naskah Serat Prabangkara karya Ki Padmasusastra mengandung pesan atau nilai-nilai pendidikan karakter yang mampu memengaruhi perilaku seseorang. Adapun nilai-nilai pendidikan yang dapat ditemukan dalam naskah Serat Prabangkara adalah sebagai berikut:

\section{a. Nilai pendidikan karakter dalam hubungannya dengan Tuhan}

Berikut nilai pendidikan karakter religius dalam Serat Prabangkara:

Ora ana, iya mung saka kêncênging ati sarta kalawan pitulunging Allah. (H27P1)

Terjemahannya:

Tidak ada, ya hanya karena bulatnya tekatku dan dengan pertolongan Allah.

Dari kutipan di atas tergambar bahwa Pangeran Adipati Prabangkara selalu melibatkan Allah dalam segala kegiatanya.

\section{b. Nilai pendidikan karakter dalam hubungannya dengan diri sendiri}

Berikut adalah nilai pendidikan karakter jujur yang terdapat dalam Serat Prabangkara:

...awit salamine kula dèrèng nate utawi botên badhe sinau wicantên dora, niku têmên mugi samang andêl wicantên kula wau.. (H36)

Terjemahan:

...karena selama ini saya belum pernah atau tidak akan berkata bohong, itu benar adanya dan semoga Anda percaya omongan saya tadi...

Dari kutipan tersebut tergambar ketika Pangeran Adipati Prabangkara berkata kepada Ki

Umbul Pedhakbrama Terjemahannya:

Setelah Sang Prabu Bramarkata mendengar laporan pengintai jika kota Indhu dalam keadaan kosong sangat menjadikan hatinya kecewa. Jika dilanjutkan menyerbu kota yang kosong akan jelek sifat manusia. Sehingga hanya ingin kembali, namun ingin berhenti sebentar mengistirahatkan para adbinya. 
Nilai pendidikan karakter di atas mengajarkan pembaca agar dapat mematuhi segala aturan-aturan sosial. Nilai ini nampak ketika Prabu Bramarkata mengurungkan niatnya untuk menyerbu kerajaan Indhu karena kerajaan Indhu dalam keadaan kosong.

\section{c. Nilai pendidikan karakter dalam hubungannya dengan sesama}

Berikut adalah nilai pendidikan karakter patuh pada aturan sosial yang terdapat dalam Serat Prabangkara:

Sarêng Sang Prabu Bramarkata midhangêt aturing juru panuksma yèn kitha ing Indhu pinanggih suwêng sangêt andadosakên cuwaning galih, yèn kalajêngakên ngrabasa kitha suwêng awon loking jana, karsanipun namung badhe wangsul, ananging badhe kèndêl sawatawis angasokaken ingkang para abdi. (H58)

\section{d. Nilai pendidikan karakter dalam hubungannya dengan lingkungan}

Berikut adalah nilai pendidikan karakter Peduli social yang terdapat dalam Serat Prabangkara:

Kacariyos Jaka Gêniroga sampun kalampahan angirup tiyang, ewon ingkang sami andon nyambut damêl, anggili botên wontên pêdhotipun, wusana malah sami katrêm gêgriya wontên ing ngriku, amargi saking mirah sandhang pangan,...(H52)

Terjemahannya:

Diceritakan Jaka Geniroga sudah berhasil mengumpulkan orang, ribuan pada ikut bekerja, mengalir tidak ada putusnya. Akhirnya bahkan pada berumah di situ, karena murah sandang

\section{e. Nilai kebangsaan} dan pangan.

Nilai kebangsaan dapat dilihat pada Pangeran Ondapawaka ketika mendengar negaranya kedatangan musuh, maka ia segera bergegas untuk mengahadapinya walaupun masih dalam keadaan berkabung karena kematian istrinya. Berikut adalah nilai pendidikan karakter patuh pada aturan sosial yang terdapat dalam Serat Prabangkara:

Kacariyos Pangeran Ôndapawaka, ingkang kapatah têngga kadhatonipun ingkang raka sang prabu, sawêg kasêkêlan galih mêntas kasedan garwa, namung tilar putra putri satunggal sarta sampun diwasa, sarêng sang pangeran midhangêt aturing bupati nayaka ingkang jagi nagari wontên parangmuka dhatêng, lajêng adhêdhawuh kinèn samêkta amapagakên mêngsah... (H58-59)

Terjemahannya:

Diceritakan Pangeran Ondapawaka, yang bertugas menunggu kerajaan kakaknya, Sang Prabu, sedang berduka setelah kematian istrinya. Hanya meninggalkan anak perempuan satu serta sudah dewasa. Setelah Sang Pangeran mendengar laporan pemimpin prajurit yang menjaga Negara bahwa ada musuh datang. Lalu (Pangeran Ondapawaka) menyuruh untuk segera menyambut musuh, Sang Pangeran bersedia menghadapi sendiri memimpin barisan menjadi pemimpin perang. 


\section{Pembahasan}

Berdasarkan hasil penelitian yang dilakukan melalui penganalisisan data maka diketahui bahwa tema dalam novel tersebut menceritakan tentang percintaan. Dalam Serat Prabangkara melalui tokoh utama Pangeran Adipati Prabangkara lebih rela memilih hidup menderita keluar dari kerajaan asalkan dapat hidup berdua dengan kekasihnya, Rara Apyu. Tokoh dan penokohan yang ada dalam Serat Prabangkara adalah tokoh yang mewakili pikiran penulis. Tokoh-tokoh itu diperhidup dengan cerita yang menyertainya. Tokoh utama dalam Serat Prabangkara adalah Pangeran Adipati Prabangkara, seorang putra raja yang gagah, tampan, rendah hati, namun tidak patuh pada perintah ayahnya, karena ayahnya terlalu memaksakan kehendaknya; Rara Apyu, digambargan sebagai wanita yang sangat sempurna secara fisik. Ia berkepribadian baik, namun juga memliki prinsip yang kuat. Berkenaan dengan karakter tokoh Serat Prabangkara pengarang mampu melukiskan perwatakan tokoh yang terungkap melalui penampilan fisik, tindakan, maupun psikisnya. Dalam Serat Prabangkara ini karakter tokoh secara garis besar menjunjung tinggi adat budaya Jawa. Hal itu tidak terlepas dari peran pengarang, yaitu Ki Padmasusastra yang berasal dari Jawa (Surakarta). Dengan demikian aspek tata krama, unggah-ungguh basa, priyayi dan wong cilik merupakan hal yang sangat melekat dalam Serat Prabangkara.

Dalam budaya Jawa struktur dan fungsi peran perempuan dalam masyarakat dianggap dalam posisi di bawah kekuasaan lelaki- lelaki. Kebanyakan tokoh-tokoh perempuan dalam novel ini mengalami perlakuan diskriminasi yang diakibatkan oleh persepsi budaya dalam sistem patriarkhi. Perempuan Jawa dalam sistem patriarkhi menempatkan perempuan sebagai sosok yang lemah lembut tidak boleh berperilaku kasar. Alur dalam Serat Prabangkara adalah maju. Plot dalam Serat Prabangkara berbeda dengan plot dalam cerita lain, karena cerita Serat Prabangkara terbagi menjadi 5 episode yang masing-masing episode dikisahkan oleh tokoh sentralnya. Cerita diawali dari kisah kepergian Pangeran Adipati Prabangkara untuk mencari kekasihnya, Rara Apyu dan diakhiri dengan pernikahan antara Pangeran Adipati Prabangkara dengan Rara Apyu. Cerita Serat Prabangkara terbagi menjadi 5 episode, oleh karena itu alur dalam Serat Prabangkara juga terbagi menjadi 5 bagian. Begitu juga tahapan alur dalam Serat Prabangkara terjadi 5 kali dalam satu cerita. Cerita bergerak secara terus menerus dan sempat denouement di episode 4, namun cerita kembali ada peningkatan dan berakhir di episode 5. Alur seperti itu juga menjadikan cerita Serat Prabangkara unik dan menarik untuk dibaca. 
Penelitian tentang kajian struktural Serat Prabangkara ini, jika dibandingkan dengan penelitian terdahulu yang relevan seperti yang dilakukan oleh Budi Mulyadi (2007) dengan judul "Karakter Tokoh Utama Novel Utsukushisa To Kanashimi To Karya Kawabata Yasunari”, Sutrimah (2013) dengan judul "Kajian Psikologi Sastra dan Nilai Pendidikan Novel Cinta Suci Zahra Karya Habiburrahman El Shirazy”, Masnuatul Hawa (2012) dengan judul "Novel Ranah 3 Warna Karya Ahmad Fuadi (Analisis Psikologi Sastra dan Nilai Pendidikan)", Krisna Pebriawan dengan judul (2012) "Novel Suparto Brata's Omnibus (Pendekatan Sosiologi Sastra dan Nilai Pendidikan), dan Muhammad Shidiq Laksananto (2013) dengan judul "Sêrat Pêthikan Pustakaraja Purwa Transliterasi, Analisis Struktur, dan Pemahaman Estetik", maka penelitian ini mempunyai persamaan dan perbedaan. Persamaannya adalah sama-sama mengkaji sebuah karya sastra fiksi dengan pendekatan sturktural sastra. Adapun perbedaannya dengan Serat Prabangkara ini terletak pada analisis struktur karya sastra pada Serat Prabangkara ini hanya mencakup empat aspek struktur sastra, yaitu tema, alur, tokoh, dan penokohan. Hal tersebut didasarkan karena keempat aspek tersebut yang mempunyai hubungan dengan psikologi sastra.

\section{Aspek Id dalam Serat Prabangkara}

Id adalah sistem kepribadian yang paling dasar, sistem yang di dalamnya terdapat naluri-naluri bawaan. Aspek id ini digambarkan oleh para tokoh dalam Serat Prabangkara melalui tingkah laku para tokohnya. Sebagai contoh ketika id dalam diri Pangeran Adipati Prabangkara bergerak dalam tubuhnya. Saat Pangeran Adipati Prabangkara ingin memilih pergi dengan Rara Apyu untuk menjalani hidup mandiri di tempat lain. Dengan demikian Ia rela meninggalkan tugas kerajaan dan keluarga. Hal tersebut merupakan dorongan id dari dalam dirinya yang bersifat egois dan menghindari ketidakenakan.

Berdasarkan cerita tersebut, diketahui bahwa cinta merupakan kebutuhan dasar atau naluri yang dimiliki oleh setiap manusia. Termasuk juga dalam diri Pangeran Adipati Prabangkara berkeinginan untuk menjalin cinta serta menjalani hidup berdua dengan Rara Apyu. Oleh karena itu tanpa menghiraukan kewajiban lainnya maupun norma-norma yang berlaku dalam masyarakat, $i d$ tersebut bertindak sewenang-wenang dan ingin segera terpenuhi. Jika hal tersebut dapat terpenuhi, maka terpuaskanlah hasrat Pangeran Adipati Prabangkara.

\section{Aspek Ego dalam Serat Prabangkara}

Pada dasarnya ego adalah sistem kepribadian yang bertindak sebagai pengarah individu kepada dunia objek dari kenyataan, dan menjalankan fungsinya berdasarkan prinsip kenyataan (reality principle). Aspek id ini digambarkan oleh para tokoh dalam Serat Prabangkara 
melalui tingkah laku para tokohnya. Dalam penggambaran ego, pengarang menampilkan melalui aktivitas serta dialog para tokohnya. Dalam perannya ego berusaha merealisasikan id seteleh mendapat persetujuan dari superego. Tetapi dalam situasi tertentu terkadang ego menjalankan tugasnya sendiri tanpa meminta saran kepada superego. Hal ini terjadi karena dorongan id lebih kuat daripada superego yang beusaha mencapai nilai-nilai moralitas. Penggambaran aspek ego dalam Serat Prabangkara dapat tergambar pada contoh berikut ini. Pangeran Adipati Prabangkara (tokoh utama dalam novel) berusaha pergi dari kerajaan agar tetap dapat hidup berdua dengan Rara Apyu. Hal tersebut dilakukan karena Prabu Ondakara (ayah Pangeran Adipati Prabangkara) tidak menyetujui hubungan cintanya dengan Rara Apyu, karena status sosial Rara Apyu yang bukan dari keturunan raja. Lalu karena tekat Pangeran Adipati Prabangkara sangat kuat untuk dapat hidup bersama dengan Rara Apyu, sehingga mendorong ego untuk merealisasikan keinginannya yang sudah tidak dapat dibendung lagi.

\section{Aspek Superego dalam Serat Prabangkara}

Pada dasarnya Superego merupakan sistem kepribadian yang berisikan nilai-nilai dan aturan-aturan yang sifatnya evaluatif (menyangkut baik buruk). Dengan tugas dan fungsinya masing-masing, ego, dan superego menggunakan energi psikis dengan hasil atau dampak yang berbeda terhadap kepribadian individu. Dari data pada analisis, superego tergambar dari niat Pangeran Adipati Prabangkara untuk mengajak Rara Apyu pergi dan menjalani hidup baru memang sudah dipikirkan terlebih dahulu dengan memertimbangkan hal-hal menjadi penyebab maupun dampaknya. Sehingga dampak buruk yang akan diterima oleh Pangeran Adipati Prabangkara memang sudah dipertimbangkan dengan baik. Berkenaan dengan kajian aspek id, ego, dan superego, penelitian Serat Prabangkara ini mempunyai persamaan dan perbedaan jika dibandingkan penelitian terdahulu yang relevan seperti yang dilakukan oleh Prima Rofik Mustofa (2012) dalam penelitiannya yang berjudul "Perwatakan Tokoh Utama dalam Novel Garuda Putih Karya Suparto Brata”; Helyn Avinanto (2013) dalam penelitiannya yang berjudul "Analisis Psikologi Novel Kawin Kontrak Kau Ingin Nama, Cinta, dan Tubuhku Karya Saifur Rohman" Dari penelitian psikologi sastra pada "Novel Kawin Kontrak Kau Ingin Nama, Cinta, dan Tubuhku”, karya Saifur Rohman; Jiang Zhu dan Yuxiao Bao dengan judul Analysis on the Character of Clyde in An America Tragedyby Tripartite Personality Stucture Theory (Theory and Practice in Language Studies Journal, Vol. 2, No. 12 December 2012, pp. 2556-2560); Maryam Harati dan Fatemah Sadat Barisizadeh dengan judul Oedipal Identity of the Patriarch in Grabiel Garcia Marquez's The Autumn of The Patriarch (Canadian Sosial Science Jornal, Vol. 7, No. 5, 2011, pp. 140-143); 
yang ditinjau dengan teori psikoanalisis Sigmund Freud. Dalam penelitian terdahulu tersebut Tokoh yang dibahas dalam penelitian adalah tokoh utama.

Persamaan penelitian tersebut dengan Serat Prabangkara adalah menggunakan ketiga struktur kepribadian Freud yaitu $i d$, ego dan superego. Disaat $i d$ ada, disitu akan muncul ego dan bahkan superego. Adapun perbedaannya adalah dalam penelitian terdahulu tersebut hanya mengulas tentang kepribadian tokoh utama dalam cerita, sedangkan dalam penelitian psikologi Serat Prabangkara ini mengungkap kepribadian semua tokoh yang berperan penting dalam menggerakkan cerita, termasuk di dalamnya adalah tokoh tambahan.

Dari paparan di atas, telah menunjukkan bahwa kajian psikologi sastra memang terkait dengan unsur instrinsik cerita, terutama perwatakan maupun aktivitas tokoh (karakter). Sementara itu, supaya cerita dapat dipahami keseluruhan maknanya, maka unsur karakter (tokoh, watak, maupun aktivitas tokoh) harus saling berkaitan dengan unsur lain seperti tema, plot, dan latar cerita.

\section{Nilai Pendidikan Karakter dalam Serat Prabangkara}

Nilai-nilai pendidikan sangat erat kaitannya dengan sebuah karya sastra, Setiap karya sastra berusaha mengungkapkan nilai-nilai luhur yang bermanfaat bagi pembacanya. Dengan membaca sebuah karya sastra, penikmat sastra diharapkan dapat mengambil nilai-nilai luhur yang terkandung di dalamnya, sehingga dapat tuntunan maupun cerminan dalam kehidupan. Serat Prabangkara adalah salah satu karya sastra yang mengandung 5 nilai pendidikan karakter utama seperti penjelasan di atas yang tentunya bermanfaat bagi kehidupan manusia.

\section{a. Nilai Pendidikan Karakter dalam Hubungannya dengan Tuhan}

Sikap religius adalah suatu sikap seseorang untuk memahami dan menghayati hidup dan kehidupan ini lebih dari sekedar yang lahiriah saja. Nilai pendidikan religius dalam naskah Serat Prabangkara tercermin secara tersurat melalui kata-kata Pangeran Adipati Prabangkara yang menjelaskan bahwa yang faktor yang menyebabkan dirinya dapat bertemu dengan Rara Apyu adalah karena kekuatan niat dan karena pertolongan Allah. Dalam hal tersebut tergambar bahwa Pangeran Adipati Prabangkara selalu berusaha melakukan segala hal dengan mengharap pertolongan Allah. Dari uraian tersebut dapat diambil pesan nilai pendidikan karakter religius yaitu kehidupan manusia di dunia tidak lepas dari Tuhan. Sebagai manusia beriman maka manusia wajib memohon pertolongan kepada-Nya.

\section{b. Nilai Pendidikan Karakter dalam Hubungannya dengan diri sendiri}

Dalam Serat Prabangkara, ajaran atau nilai pendidikan karakter yang berhubungan dengan diri sendiri adalah jujur, tanggung jawab, kerja keras, dan mandiri Nilai kejujuran 
tersebut nampak pada diri Pangeran Adipati Prabangkara ketika berkata kepada Ki Umbul Pedhakbrama bahwa ia tidak pernah belajar berbohong. Karena pada hakikatnya kejujuran adalah salah satu hal yang menjadi bagian amal baik manusia. Cerminan nilai pendidikan karakter tanggung jawab nampak pada diri Prabu Ondakara ketika sebelum pergi meninggalkan kerajaan ia terlebih dahulu mengadakan rapat dengan punggawa kerajaan, keluarganya, dan seluruh rakyatnya. Lalu nilai pendidikan karakter yang dapat dipetik dari kutipan di atas bahwa seorang raja haruslah bertanggung jawab pada amanah yang diembannya. Karakter kerja keras terlihat ketika Pangeran Adipati Prabangkara mencari Rara Apyu sampai ke mana-mana. Segala hambatan diterjang. Kesungguhan Pangeran Adipati Prabangkara berhasil setelah menggunakan ilmu penciuman yang dimilikinya, hingga. Akhirnya ia menemukan Rara Apyu di sebuah sendang. Nilai pendidikan karakter agar selalu hidup mandiri serta tidak tergantung pada orang lain dalam menyelesaikan tugas. Dalam hal tersebut, tergambar kemandirian Pangeran Adipati Prabangkara yang berusaha lepas dari cengkeraman orang tuanya, dan ingin menjalani hidup mandiri asalkan dapat berdua dengan Rara Apyu.

\section{c. Nilai Pendidikan Karakter dalam Hubungannya dengan Sesama}

Hakikat dari nilai pendidikan karakter dalam hubungannya dengan sesama adalah ajaran yang mendorong seseorang supaya sadar bahwa manusia tidak dapat hidup sendiri, tetapi harus bekerja sama dengan orang lain dalam rangka memenuhi kebutuhannya. Nilai pendidikan karakter dalam hubungannya dengan sesama dalam Serat Prabangkara meliputi patuh pada aturan-aturan sosial, santun dan demokrasi. Patuh pada aturan-aturan sosial Manusia hidup dalam masyarakat ini nampak ketika Prabu Bramarkata mengurungkan niatnya untuk menyerbu kerajaan Indhu karena kerajaan Indhu dalam keadaan kosong. Hal itu menunjukkan bahwa Prabu Bramarkata sangat patuh pada peraturan sosial. Dalam Serat Prabangkara sudah mengajarkan sikap santun melalui teks ceritanya, karena tersebut disajikan dengan bahasa Jawa ragam krama. Sedangkan dalam dialog antara tokoh yang berumur lebih muda menggunakan bahasa Jawa ragam krama kepada tokoh yang berumur lebih tua, begitu sebaliknya. Contohnya ketika Prabu Ondakara menggunakan ragam bahasa ngoko ketika berbicara dengan istrinya, putranya, maupun abdinya. Demikian pula sebaliknya ketika Pangeran Adipati Prabangkara berbicara dengan orang tuanya menggunakan bahasa krama. 


\section{d. Nilai Pendidikan Karakter dalam Hubungannya dengan Lingkungan}

Nilai pendidikan karakter dalam hubungannya dengan lingkungan dalam Serat Prabangkara adalah ini nampak pada tindakan yang dilakukan Prabu Bramarkata (Rara Apyu) dengan utusan Patih Bratunu (Jaka Geniroga) pada upaya mengumpulkan orang disekitar Gunung Padas agar mau bekerja di Guasiluman serta mau bertempat tinggal disitu.

\section{e. Nilai Kebangsaan}

Nilai nasionalis dalam Serat Prabangkara adalah kesetiaan, kepatuhan, dan rasa hormat seorang bawahan pada pemimpinnya, serta kesetiaan rakyat kepada negaranya. Sebagai rasa cintanya kepada tanah air atau seorang yang berjiwa nasionalis, maka sudah seharusnya rakyat menghormati pemimpinnya, serta menjunjung tinggi martabat bangsanya. Nilai Nasionalis diajarkan oleh Pangeran Ondapawaka ketika mendengar negaranya kedatangan musuh, maka ia segera bergegas untuk mengahadapinya walaupun masih dalam keadaan berkabung karena kematian istrinya. Hal tersebut membuktikan bahwa Pangeran Ondapawaka sangat mementingkan kerajaan daripada dirinya sendiri. Temuan nilai pendidikan karakter nasionalis tersebut sejalan dengan pendapat Aqib dan Sujak serta Priyanto, dkk. Penelitian mengenai pendidikan karakter dalam SeratPrabangkara, jika dibandingkan penelitian yang mengulas tentang pendidikan karakter seperti penelitian yang dilakukan oleh Titi Mumfangati (2011) dan Krisna Pebriawan (2012), maka penelitian pendidikan karakter dalam SeratPrabangkara ini mempunyai keutamaan.

Keutamaannya adalah penelitian pendidikan karakter SeratPrabangkara telah mengungkap ajaran yang berkaitan dengan Tuhan Yang Maha Esa, diri sendiri, sesama manusia, lingkungan, dan nilai kebangsaan. Nilai-nilai itu terasa lebih lengkap jika diterapkan dalam kehidupan sehari-hari. Berbeda dengan penelitian pendidikan karakter yang diungkap oleh Mumpangati dan Pebriawan, mereka berdua hanya menekankan pada pendidikan sopan santun dalam bersikap dan bertindak. Berkenaan dengan sopan santun tersebut, maka penelitian pendidikan karakter SeratPrabangkara juga telah mengulasnya secara lengkap.

\section{Simpulan}

Berdasarkan hasil penelitian dan pembahasan dapat diambil simpulan sebagai berikut. Ditinjau dari segi struktur karya sastra, Serat Prabangkara memiliki empat struktur meliputi tema, tokoh, penokohan, dan karakter. Tema dalam cerita Serat Prabangkara adalah percintaan. Adapun tokoh dan penokohan dalam Serat Prabangkara sebagian besar menggunakan nama sapaan orang Jawa, karena faktor pengarang yang berlatarbelakangkan 
Jawa. Dalam Serat Prabangkara ini karakter tokoh secara garis besar menjunjung tinggi adat budaya Jawa. Hal itu tidak terlepas dari peran pengarang, yaitu Ki Padmasusastra yang berasal dari Jawa (Surakarta). Dengan demikian aspek tata krama, tepa salira, unggahungguh basa, dan suasana sosial kaum priyayi dan wong cilik merupakan hal yang sangat melekat dalam Serat Prabangkara.

Berdasarkan analisis kepribadian para tokoh dalam Serat Prabangkara tersebut sejalan dengan teori psikoanalisis Sigmund Freud (id, ego, dan superego). Namun, teori tersebut, terkadang tidak dinampakkan ketiga-tiganya secara beriringan. Selain itu, Serat Prabangkara juga mengandung nilai pendidikan karakter yang bermanfaat bagi kehidupan manusia.

\section{Daftar Pustaka}

Aqib, Zainal dan Sujak. 2012. Panduan dan Aplikasi Pendidikan Karakter. Bandung: Yrama Widya.

Endraswara, Suwardi. 2004. Metodologi Penelitian Sastra. Yogyakarta: Pustaka Widyatama

2008. Metodologi Penelitian Sastra. Yogyakarta: Media Pressindo. .2008. Metode Penelitian Psikologi Sastra. Yogyakarta: MedPress (anggota AKAPI).

.2011. Metode Penelitian Sastra: Espitologi, Model, Teori dan Aplikasi. Yogyakarta : Center for Academic Publishing Service.

2013. Teori Kritik Sastra: Prinsip, Falsafah, dan Penerapan. Yogyakarta : Center for Academic Publishing Service.

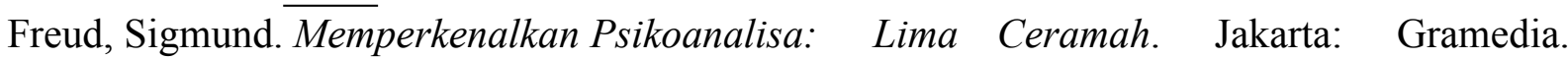
(diterjemahkan oleh K. Bertens)

Harati, Maryam and Fatemah Sadat Barisizadeh. 2011. Oedipal Identity of the Patriarch in Grabiel Garcia Marquez's The Autumn of The Patriarch. Canadian Sosial Science Jornal. Vol. 7 (5): 140-143.

Hawa, Masnuatul. 2012. Novel Ranah 3 Warna karya Ahmad Fuadi Analisis Psikologi Sastra dan Nilai Pendidikan. Tesis Program Pendidikan Bahasa Indonesia UNS. Surakarta.

Hidayatullah, M. Furqon. 2010. Pendidikan Karakter: Membangun Peradaban Bangsa. Surakarta: Yuma Pustaka.

Kusumawati, I. (2014). Pemanfaatan Potensi Budaya Lokal untuk Meningkatkan Kualitas Pembelajaran IPS Kelas IV Di Sekolah Dasar Gondok Timbulharjo Sewon Bantul. Academy of Education Journal, 5(1). 
Jamalia, Risyat. 2011. Konflik Kepribadian pada Tokoh-Tokoh dalam Novel Lintang Gumebyar (Tinjauan Psikologi Sastra). Tesis. Bandung: UPI.

Jiang Zhu dan Yuxiao Bao. 2012. Analysis on the Character of Clyde in An American Tragedy by Tripartite Personality Structure Theory. Vol 2, No 12 (2012), 2556-2560, Dec 2012 doi:10.4304/tpls.2.12.2556-2560. Theory and Practice in Language Studies.

Karatay, Hatit. 2011. Karakter Ĕ̈itiiminde Edebi Eserlerin Kullanimi (Using Literary Works in Character Education). International Periodical for the Language,Literature, and History of Turkish or Turkic, Vol. 6 (1): 1398-1412.

Kwatsha, L. L. 2007. A psychoanalytical interpretation of the characters in A.C. Jordan's novel Ingqumbo yeminyanya. Literator 28(3) Des./Dec. 2007:75-89.

Minderop, Albertine. 2011. Psikologi Sastra: Karya Sastra, Metode, Teori, dan Contoh Kasus. Jakarta: Yayasan Pustaka Obor Indonesia.

Moleong, Lexy J. 2010. Metodologi Penelitian Kualitatif. Bandung: PT RemajaRosdakarya. Nugroho, Akhmad. 2010. Demokratisasi Ki Padmasusastra dalam Bahasa, Sastra, dan Budaya Jawa. Makalah Seminar Nasional. Surakarta 29 November 2010.

Nurgiyantoro, Burhan. 2005. Teori Pengkajian Fiksi. Yogyakarta : Gajah Mada University Press.

Nuryati, N., \& Bowo, A. N. A. (2015). Pengembangan Model Pembelajaran PPKn Quantum Teaching Berbasis Lingkungan melalui Cooperative Learning di SMA Negeri kota Yogyakarta. Academy of Education Journal, 6(2).

Noor, Rohinah M.. 2011. Pendidikan Karakter Berbasis Sastra: SOLUSI Pendidikan Moral yang Efektif. Jogjakarta: Ar-Ruzz Media.

Sarwiji, Suwandi. 2013. Jurnal Wacana Bahasa dan Sastra. PBI PPs. UNS. Vol. 11, No. 1, Hal. 1-102, Surakarta, April 2013.

Semi, Atar. 1993. Metode Penelitian Sastra. Bandung : Angkasa.

1989. Kritik Sastra. Bandung: Angkasa.

Subroto, D. Edi. 2007. Pengantar Metode Penelitian Linguistik Struktural. Surakarta: LPP UNS dan UNS Press.

Sudjiman, Panuti. 1988. Memahami Cerita Rekaan. Jakarta: Pustaka Jaya.

Supardjo. 2010. Ki Padmasusastra "Tiyang Mardika ingkang Amarsudi ing Kasusastran Jawi” (Sang Pujangga dan Karya-Karyanya). Seminar Nasional, FSSR UNS Surakarta, 29 November 2010.

Sutopo, H.B. 2006. Metodologi Penelitian Kualitatif Dasar Teoritis dan Terapannya dalam Penelitian. Surakarta: UNS Press. 
Sutrimah, 2013. Kajian Psikologi Sastra dan Nilai Pendidikan Novel Cinta Suci Zahrana karya Habiburrahman El Shirazy. Tesis Program Pendidikan Bahasa Indonesia UNS. Surakarta.

Titi Mumfangati. 2011. Pendidikan Budi Pekerti dalam Budaya Jawa Kajian terhadap Serat Nitipraja. Vol. VI, No. 12, (Desember 2011), Hal. 198-207. Jantra Jurnal Sejarah dan Budaya.

Waluyo, Herman J. 2002. Pengkajian Sastra Rekaan. Salatiga: Widya Sari Press. . 2002. Drama, Teori dan Pengajarannya. Yogyakarta: Hanindita. . 2006. Teori Pengkajian Sastra. Surakarta: UNS Press. 